\title{
Non bis in idem en Derecho antitrust
}

\author{
Alfonso Luis Calvo Caravaca \\ Catedrático de Derecho Internacional Privado \\ Universidad Carlos III de Madrid \\ $\mathrm{y}$ \\ María Pilar Canedo Arrillaga
}

Profesora doctora de Derecho Internacional Privado

Universidad de Deusto

Resumen: Este artículo pretende poner de manifiesto las implicaciones que supone la apreciación del principio non bis in idem por parte de las autoridades administrativas sancionadoras y, en especial, por parte de la Comisión Europea. La potestad sancionadora de esta institución en materia de Derecho de la Competencia ha servido para que el Tribunal de Justicia de las Comunidades Europeas se pronuncie sobre este particular emitiendo resoluciones objeto de estudio y crítica en este trabajo.

Palabras clave: Non bis in idem. Competencia Derecho Comunitario.

Abstract: The object of this essay is to analise the different implications of the application of the principle of double jeopardy by administrative authorities with power to impose sanctions and specially the European Commission.

The power of the Commission to impose sanctions and injunctions in the field of European Competition Law has given the possibility to the European Court of Justice to pronounce interesting judgements that are analysed in a critical way in this article.

Key words: Double jeopardy. Competition Law. European Union Law.

Sumario: I. Planteamiento.-II. Concurso de leyes y non bis in idem.-III. El concurso de infracciones: 1. El concurso ideal. 2. El concurso real. - IV. La relación de los diferentes concursos con el principio non bis in idem. - V. La relación del principio non bis in idem con las normas que tipifican las conductas: La incidencia del interés jurídico protegido.VI. Requisitos del principio non bis in idem: 1. Elemento causal. 2. Elemento objetivo: Unidad o pluralidad de hechos y acciones. - VII. Dinámica de la regla: 1. La vertiente material del principio. 2. La vertiente procesal del principio.-VIII. El principio non bis in idem en Derecho europeo de la competencia: 1. Concepto y naturaleza jurídica. 2. Origen. 3. Dobles sanciones en virtud del Derecho comunitario. 4. Dobles sanciones en relación a las sanciones de los Estados miembros. 5. Dobles sanciones en relación a terceros Estados. 6. El Reglamento 1/2003. 


\section{Planteamiento}

1. Cabe preguntarse en qué medida diversos mecanismos jurídicos en los ámbitos comunitario y administrativo impiden un cúmulo de sanciones de una misma conducta. Grosso modo, según el principio non bis in idem (también conocido como ne bis in idem) o regla de la no acumulación de sanciones (Verbot der Doppelbestrafung, Verbot der Doppelsanktion), una persona ya juzgada no puede ser perseguida o juzgada por el mismo hecho. Este principio - similar a la double jeopardy clause en los Estados Unidos - tiene sus orígenes en el Derecho penal; pero se extendió con carácter general al Derecho sancionador ${ }^{1}$.

2. Dicha cuestión refleja un interés práctico. Con la progresiva liberalización de las telecomunicaciones en la UE, organismos reguladores y autoridades nacionales de competencia incoan sucesivos procedimientos contra las mismas empresas por hechos esencialmente idénticos o, al menos, muy semejantes ${ }^{2}$.

3. Cuando la conducta que se imputa a una empresa es susceptible de afectar al comercio intracomunitario (Zwischenstaatsklausel), es aplicable el Derecho comunitario de la competencia ${ }^{3}$. Conforme al Reglamento $1 / 2003$, pueden ser competentes, en principio, tanto la Comisión como las

${ }^{1}$ En el orden interno, la doctrina y la jurisprudencia han justificado este principio con tres motivos: nemo debet bis vexari pro una et eadem causa, el Erledigungsprinzip y la idea de que res iudicata pro veritate habetur. Vid., ad ex., CANO CAMPOS, T., «Non bis in idem, prevalencia de la vía penal y teoría de los concursos en el Derecho administrativo sancionador», Revista de Administración Pública, n. ${ }^{\circ}$ 156, septiembre-diciembre 2001, pp. 191249; Dawson, M.A., «Popular Sovereignity, Double Jeopardy, and the Dual Sovereignity Doctrine», Yale Law Journal, 1992, pp. 281-303; HeERS, M., «Le principe non bis in idem devant le juge administratif français: L'application en droit interne d'une garantie procédurale consacrée par les systèmes internationaux de protection des droits de l'homme», Revue trimestrielle desdroits de l'homme, 7, 25, 1996, pp. 35-44; De LeÓn Villalba, F. J., Acumulación de sanciones penales y administrativas. Sentido y alcance del principio ne bis in idem, Barcelona, 1998; VAN DEN WyngaerT, C./STESSENS, G., «The international non bis in idem principle: resolving some of the unanswered questions», Int.Comp.L.Q., 48, 4, 1999, pp. 779-804.

${ }^{2}$ Vid., ad ex., la decisión n. ${ }^{0}$ 5-D-59 del Conseil de la concurrence francés de 7 noviembre 2005 relativa a prácticas realizadas por la sociedad France Télécom en el sector de Internet de alta velocidad (ADSL), comentada por PRIETO, C. Concurrences, n. ${ }^{\circ}$ 1, 2006, pp. 141-142, que impuso al operador histórico francés una multa de 80 millones de euros por abuso de posición dominante.

3 Sobre la afectación del comercio intracomunitario (Beeinträchtigung des zwischenstaatlicehn Handels), vid., ad ex., Bunte, H.-J., «Art. 81», en LANGEn/BunTe, Kommentar zum deutschen und europäischen Kartellrecht, 10. ${ }^{\mathrm{a} e d .,}$ vol. 2, München, 2006, pp. 45 y ss., concr. pp. 124-142; MESTMÄCKERE.-J./SCHWEIZER, H., Europäisches Wettbewerbsrecht, München, 2004, pp. 129-139. 
autoridades nacionales. Si es competente la Comisión, aplicará Derecho comunitario. Si es competente una autoridad nacional de la competencia, también deberá aplicarlo. Pero, si conoce de un abuso de posición dominante, esta autoridad nacional podrá aplicar también su propia legislación, cuando sea más rigurosa que la comunitaria.

4. Cuando la conducta no sea susceptible de afectar al comercio intracomunitario, la competencia y normativa aplicable se determinarán conforme al ordenamiento jurídico del Estado respectivo.

5. Por tanto, para responder a la pregunta inicial, analizaremos el principio non bis in idem en Derecho español y en Derecho comunitario de la competencia.

\section{Concurso de leyes y non bis in idem}

6. La relación entre el principio non bis in idem y el concurso de leyes ha sido de influencia mutua. Así, desde una perspectiva material, se ha tratado de buscar justificación al principio non bis in idem. Generalmente, la doctrina entiende que éste es el resultado y el correctivo necesario de un concurso de leyes y que, por lo tanto, cabe aplicar, mutatis mutandis, las teorías que a este respecto se han construido dentro de la doctrina penal.

7. La teoría penal del concurso de leyes aborda una situación en la que, en apariencia, una duplicidad de normas, de forma válida, tipifican y sancionan una misma conducta ${ }^{4}$. En ese caso, podría, en principio, concluirse que, puesto que parece que existen dos normas tipificadoras válidas, habría que aplicar ambas; ya que la misma acción constituye dos o más delitos o infracciones. Esta situación tendría, como resultado, la aplicación simultánea de todas esas normas y la duplicidad de la sanción ante un mismo hecho, fundamento y sujeto.

8. Por el contrario, el principio non bis in idem permite bloquear esa superposición de sanciones que se considera injusta. En el concurso de leyes, de las diversas normas aparentemente aplicables a un mismo hecho, sólo una de ellas es realmente aplicable. Las demás normas quedan desplazadas conforme a diversos criterios interpretativos, ya desde hace tiempo elaborados por la doctrina y la jurisprudencia penales. Para evitar, por tanto, el resultado injusto antes mencionado, se recurre a las normas del concurso de leyes ${ }^{5}$.

4 Vid., per omnia, PeÑARANDA RAmos, E., Concurso de leyes, error y participación en el delito, Madrid, 1991, pp. 35 y ss.

5 Muñoz Conde, F./García Adan, M., Derecho Penal. Parte General, 2. ${ }^{\text {a }}$ ed., Valencia, 1996, p. 488. 
9. Los tribunales y autores recurren al principio non bis in idem en casos en los que se da esa misma situación: La existencia de dos normas aparentemente aplicables, aunque sólo una de ellas resulta acorde con los hechos sucedidos. Por ello, para dar solución a los casos en que se produce un supuesto de colisión con el principio de non bis in idem, se aplican las teorías formuladas en Derecho Penal para enfrentarse al concurso de leyes.

10. El problema radicaría en determinar cuál de las normas sancionadoras aparentemente aplicables prevalece en el caso del concurso y cuál es la que debe quedar marginada. Para ello pueden utilizarse una serie de criterios de ponderación, actualmente recogidos en el art. 8 del Código penal español:

a) Según el criterio de la especialidad, la ley especial prevalece sobre la general e impide la aplicación de ésta. A estos efectos, se entiende por ley especial la que describe un tipo en que aparecen todos los elementos de otro; pero, a él, se añaden algunas características específicas. De acuerdo con este criterio, se aplicará el tipo que sea capaz de abarcar el total del contenido del injusto, en detrimento de aquél o aquéllos en que tan sólo se contengan aspectos parciales del mismo.

b) El criterio de subsidiariedad implica que una de las normas sólo entrará en juego en el supuesto de que otra no pueda hacerlo: «El precepto subsidiario se aplicará sólo en defecto del principal, ya se declare expresamente dicha subsidiariedad, ya sea ésta tácitamente deducible» (art. 8, párrafo segundo, del Código penal español). Este criterio tiene en el Derecho sancionador la finalidad de evitar que la concurrencia de determinados requisitos deje sin sanción un hecho que, de todos modos, puede ser sancionado por otro precepto que no exige esos requisitos.

c) El criterio de consunción tiene lugar cuando un delito engloba hechos ya de por sí constitutivos de delitos que no se castigan autónomamente; porque su desvalor va incluido ya en el desvalor del delito del que forman parte.

d) El criterio de alternatividad se dará en el caso de que no se apliquen ninguno de los criterios anteriores e implica que los hechos susceptibles de ser calificados con arreglo a dos o más preceptos de un determinado cuerpo legal lo serán tan sólo por aquél de ellos que contenga mayor sanción para el ilícito cometido ${ }^{6}$.

6 SAnZ Morán, L., «El concurso de delitos en la reforma penal» en AA.VV., Unidad y pluralidad de delitos, Cuadernos de Derecho Judicial, 1995, pp. 230 y ss. 
11. Como puede deducirse de lo que acabamos de decir, el concurso de leyes implica simplemente un problema de interpretación para determinar la ley o precepto efectivamente aplicable a una determinada controversia: En un supuesto de hecho, resultan aparentemente aplicables varios preceptos; pero el desvalor que representa el supuesto de hecho es abarcado por uno de los preceptos concurrentes, cuya aplicación excluye a los demás. Cuando dos preceptos concurrentes tienen el mismo núcleo fundamental, sólo uno de ellos puede ser aplicable, debiendo excluirse la aplicación de los otros.

Si la doble punición que da lugar a que se plantee la aplicación del principio de non bis in idem deriva de un concurso de leyes, su solución podrá alcanzarse mediante la adecuada interpretación de los preceptos aparentemente aplicables que determinará cuál de ellos debe prevalecer.

12. Estos criterios originariamente diseñados en el ámbito penal son extrapolables al Derecho administrativo. Su transposición resulta, sin embargo, más dudosa cuando el concurso es interordinamental y, en concreto, cuando la colisión tiene lugar entre una norma de carácter administrativo y otra penal. En ese caso, en nuestro ordenamiento rige el criterio de subsidiariedad de la norma administrativa, razón por la cual la norma penal recibe aplicación de modo prevalente ${ }^{7}$.

\section{El concurso de infracciones}

13. Otra de las causas que puede dar lugar a una doble punición es la existencia de lo que se conoce como concurso de delitos, tradicionalmente estructurado en concurso ideal y concurso real.

14. Junto a ellos, se habla, a veces, del concurso medial: Es aquél en el que la comisión del delito no supone un fin en sí mismo, sino que se trata de un medio para realizar otro. En este supuesto, nos encontramos ante dos hechos y dos delitos, por lo que, en principio, debería producirse una acumulación de la sanción. Sin embargo, suele adoptarse la misma solución que para el concurso ideal, optando por la imposición de la pena más grave de las disponibles.

15. Cuando una sola acción infringe varias disposiciones legales o varias veces la misma disposición - es decir, cuando con una sola acción se cometen varios tipos delictivos homogéneos o heterogéneos - surge el denominado concurso ideal. En este caso, si se aplica el principio non bis in

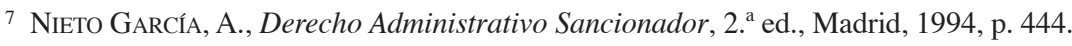


idem, la consecuencia es que uno de los delitos quedará impune; mientras que, si se castigan los dos, se quebranta el principio, lo cual tampoco se considera tolerable. Para solucionar este conflicto, el Derecho penal articula la teoría de los concursos 8 .

16. Cuando concurren varias acciones o hechos cada uno de los cuales es constitutivo de un delito autónomo, se produce el denominado concurso real. En principio, este concurso no plantea ningún problema teórico: Cada acción por separado constituye un delito y, por tanto, el tratamiento debería ser la acumulación de las sanciones. La existencia de varios hechos nos lleva a concluir que, en el caso de un concurso real, no estaríamos en el supuesto del non bis in idem. Sin embargo, incluso en este caso, el ordenamiento prevé mecanismos de corrección de las sanciones ${ }^{9}$.

17. El problema común a todos los supuestos de concurso citados es determinar cuándo existe una o varias acciones. Cuando una sola acción realiza un tipo nos encontramos con el caso normal. Cuando una o varias acciones realizan varios tipos delictivos surgen los problemas del concurso.

En principio, hay que excluir la identificación entre acción y movimiento corporal y la identificación entre acción y resultado. Resulta posible que una acción en sentido jurídico pueda contener varios movimientos y dar lugar a varios resultados. Por ello, hay que acudir a otros factores para determinar la unidad de acción: El primero es el factor final que atiende a la voluntad que rige y da sentido a una pluralidad de actos físicos aislados. El segundo factor será el normativo, que atiende a la estructura del tipo en cada caso particular. De este modo, «aunque el factor final que rige el proceso causal sea el mismo, alguno de los actos particulares realizados puede tener, aisladamente, relevancia para distintos tipos delictivos. A la inversa, actos aislados cada uno regido por un factor final distinto, pueden tener relevancia típica sólo cuando se dan conjuntamente o tener una relevancia distinta en función de la regulación del hecho correspondiente al tipo» ${ }^{10}$.

\section{El concurso ideal}

18. Tal como hemos señalado, cuando un solo hecho constituya dos o más infracciones nos encontramos con el caso de concurso ideal. Eviden-

8 Sobre la incidencia de la teoría de los concursos en la determinación de la pena, CuERDA Riezu, A., Concurso de delitos y determinación de la pena, Madrid, 1992, pp. 25 y ss., en que se explican en profundidad las diversas soluciones que el legislador puede establecer ante un concurso de infracciones.

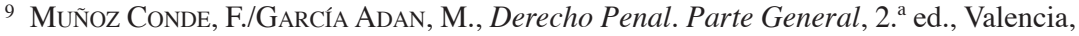
1996 , pp. 477 y ss.

10 Ibidem, p. 479. 
temente no resulta posible valorar igual una acción que produce un solo delito que esa misma acción cuando conlleva varios resultados delictivos; ya que, en este caso, la aplicación de uno solo de los tipos no agotaría la valoración total de la acción. Sólo la aplicación simultánea de todos los tipos realizados por la acción valora plenamente el suceso; aunque después la sanción resultante deba ser atemperada.

Precisamente la diferencia existente entre el concurso ideal y el concurso de leyes consiste en que en el concurso de leyes son aparentemente aplicables diversos preceptos, pero su correcta interpretación determina que tan sólo uno de ellos lo es realmente. En el concurso ideal, todos los preceptos infringidos por la acción son aplicables y solamente hay algunas puntualizaciones respecto de la sanción a imponer.

19. El problema básico para determinar la aplicación de estas teorías es la consideración de cuándo nos encontramos ante un solo hecho. La unidad de hecho equivale a la unidad de acción y ésta existirá cuando la actuación corresponda a una misma manifestación de voluntad y sea valorada unitariamente en el tipo.

La producción de varios delitos no equivale a la realización de varias acciones; ya que entonces la diferencia entre concurso ideal y real no tendría sentido. Sin embargo la dificultad de fijar cuándo hay un solo hecho o una sola acción y cuándo varias hace que, en la práctica, exista gran inseguridad a la hora de aplicar ambas modalidades de concurso.

20. La consecuencia más importante de la existencia del concurso ideal se centra en el problema de la determinación de la pena. Para darle solución, el legislador puede acudir a diferentes criterios: El principio de acumulación implica que la pena de cada infracción se determina de forma separada y luego se suman; el principio de absorción determina la aplicación únicamente de la pena más grave de entre las posibles; el denominado principio de asperación entraña la imposición de la pena más grave agravada; el principio de combinación impone la mezcla de las diferentes penas aplicables en una sola.

Corresponde al legislador a la hora de diseñar el sistema punitivo tanto la opción por alguno de estos sistemas de determinación de la pena como la opción de combinar la aplicación de todos estos criterios o, al menos, algunos de ellos. De hecho, en nuestro ordenamiento jurídico penal se opta por el principio de asperación, razón por la cual el art. 77, párrafo segundo, del Código Penal recoge que se aplicará en su mitad superior la pena prevista para la infracción más grave. Sin embargo, cuando de este modo la pena concreta resulte más grave que la suma de las penas concretas que pudieran imponerse penando por separado los delitos, se sancionarán por separado aplicando el principio de acumulación. 
En todo caso, en aras del principio de proporcionalidad, el legislador debería tratar de forma más benigna el concurso ideal que el real, que se expone a continuación.

\section{El concurso real}

21. El concurso real se produce cuando concurren varias acciones y cada una de ellas es constitutiva de un delito. En principio, esta situación no plantea problema teórico; ya que cada acción por separado constituye un delito y su tratamiento jurídico podría seguir el principio de acumulación.

No obstante, la aplicación sin limitaciones del principio de acumulación puede llevar a la determinación de penas excesivas e incompatibles con la valoración global de todos los delitos y la sensibilidad jurídica ${ }^{11}$. Para evitar estas consecuencias, el ordenamiento recoge ciertos criterios que pretenden la fijación de penas proporcionadas a la valoración global de las acciones cometidas.

De este modo, incluso en el caso del concurso real, el principio de acumulación suele ser corregido mediante el principio de asperación. Así, ad ex., en nuestro ordenamiento jurídico, el Código Penal recoge que «cuando todas o algunas de las penas correspondientes a las diversas infracciones no puedan ser cumplidas simultáneamente por el condenado, se seguirá el orden de su respectiva gravedad para su cumplimiento sucesivo» (art. 75). Sin embargo, «el máximo de cumplimiento de la condena del culpable no podrá exceder del triple de tiempo por el que se impusiere la más grave de las penas en que haya incurrido, declarando extinguidas las que procedan desde que las ya impuestas cubran dicho máximo...» (art. 76 del Código penal).

Así, independientemente del número de delitos o infracciones cometidos y enjuiciados en un solo proceso, la pena no puede ser superior al triple de la más grave de las que se podrían imponer.

\section{La relación de los diferentes concursos con el principio non bis in idem}

22. Como consecuencia de todo lo anterior, se puede concluir que si hay varios hechos y cada uno está tipificado como infracción y sancionado, estaremos ante un concurso real de infracciones en el que las sanciones se acumulan y, por lo tanto, no habrá, en principio, colisión con el principio non bis in idem. Será el principio de proporcionalidad el que exija una atemperación de la sanción determinada en función del principio de acumulación.

11 Ibidem, p. 484. 
Si el hecho es único y está tipificado como infracción en varias normas sancionadoras, habrá que determinar si es un concurso ideal o aparente.

Si es un concurso aparente, el respeto al principio non bis in idem exigirá que el órgano encargado de la aplicación de las normas realice una adecuada interpretación de las mismas para determinar cuál de ellas debe imponerse.

En otro caso, podremos encontrarnos ante un concurso ideal de infracciones y el respeto al principio non bis in idem exigirá que se acuda a las normas de solución de este problema para no aplicar sanciones desproporcionadas. Por lo tanto, se aplicará la sanción en cuantía superior o sólo se aplica una de ellas al considerarla prevalente respecto del resto.

\section{La relación del principio non bis in idem con las normas que tipifican las conductas: La incidencia del interés jurídico protegido}

23. El análisis de la teoría de los concursos nos sitúa en la relación existente entre el principio non bis in idem y las normas en que se recogen las sanciones. Examinado el problema desde este punto de vista, para que se dé la posibilidad de que exista más de una sanción, como respuesta a una misma acción, debe necesariamente existir una pluralidad de normas que tipifiquen infracciones respecto de los mismos hechos. Podría, por consiguiente, modificarse la perspectiva de estudio del principio non bis in idem y acudir no tanto a la prohibición de la doble sanción, cuanto a la prohibición de la existencia de una pluralidad de tipos infractores. La pluralidad de procedimientos y sanciones sólo podría darse en el caso de que dos normas tipifiquen válidamente los mismos hechos y, por lo tanto, la protección del non bis in idem implicaría un control de esa duplicidad de normas.

La concurrencia de normas sancionadoras ante un mismo hecho sólo sería lícita si esas normas prevén sanciones por dos fundamentos o causas distintas $^{12}$. Como sostiene la STC 243/1991, de 10 de diciembre: «para que la dualidad de sanciones sea constitucionalmente admisible es necesario (...) que la normativa que la impone pueda justificarse porque contemple los hechos desde la perspectiva de un interés jurídicamente protegido que no es el mismo que aquél que la primera sanción intenta salvaguardar o, si se quiere, desde la perspectiva de una relación jurídica diferente entre sancionador y sancionado».

12 Cano Campos, T., «Non bis in idem, prevalencia de la vía penal y teoría de los concursos en el Derecho administrativo sancionador», Revista de Administración Pública, n. ${ }^{\circ} 156$, septiembre-diciembre 2001, p. 195. 
En estrecha relación con la aplicación del principio non bis in idem y la norma que recoge la sanción está, por consiguiente, la cuestión de los intereses protegidos por las normas que contienen las sanciones.

24. La razón que más frecuentemente se esgrime para justificar la lícita existencia de una pluralidad de sanciones respecto de unos mismos hechos es la protección, en cada una de las normas que las contienen, de bienes o intereses jurídicos de diferente naturaleza. Es lo que en nuestro ordenamiento jurídico sucede con las sanciones disciplinarias.

Nuestra jurisprudencia ha recurrido con profusión a esta doctrina. Como ejemplo, cabe citar la STC 234/1991, de 10 de diciembre: «No basta simplemente con la dualidad de normas para entender justificada la imposición de una doble sanción al mismo sujeto por los mismos hechos, pues, si así fuera, el principio ne bis in idem no tendría más alcance que el que el legislador, o en su caso el Gobierno como titular de la potestad reglamentaria, quisiera darle».

Sin embargo, si dos normas protegen bienes jurídicos diferentes, no resulta tan evidente la prohibición de la doble punición ${ }^{13}$. Es lo que sucede en el caso de las sanciones impuestas en relaciones de sujeción especial del ciudadano con la Administración y su relación con las sanciones ordinarias ${ }^{14}$.

De este modo, resultaría constitucionalmente admisible una doble sanción al mismo sujeto por los mismos hechos, siempre y cuando los intereses protegidos por ambas sanciones sean distintos. Expresado con otros términos, la normativa que impone la segunda infracción sólo quedará justificada; porque contemple los hechos desde la perspectiva de un interés jurídicamente protegido que no sea el mismo que aquél que la primera sanción intenta salvaguardar.

25. Esta interpretación ha sido objeto de numerosas críticas.

Cabría puntualizar, ad ex., que no son tanto los intereses que se protegen por la norma los que alteran el régimen jurídico de protección del non bis in idem, cuanto el reflejo de los mismos en el contenido de la norma ${ }^{15}$. Ello implica que la norma debe incluir en el tipo las matizaciones propias

13 «Por bien jurídico - señala CANO CAMPOS, T., Ibidem, p. 195, nota 5- ha de entenderse el objeto protegido por la norma sancionadora vulnerada (la integridad física, la seguridad, la salud, el honor, el medio ambiente, el patrimonio histórico, el correcto funcionamiento de la Administración, etc.)».

14 Pralus-Dupuy, J., «Cumul et non Cumul de Sanctions en Droit Disciplinaire», Recueil Dalloz, 1993, 19. ${ }^{\circ}$ Cahier, Chonique, pp. 135-140; Fernández Canales, C., «Potestad sancionadora de la Administración Pública y Principio non bis in idem. Comentario a la STS (Sala 3. ${ }^{a}$ Secc. 7. ${ }^{a}$ ) de 7 de julio de 1992», La Ley, 1992-4, p. 515.

15 Nieto García, A., Derecho Administrativo Sancionador, 2. a ed., Madrid, 1994, p. 406. 
del interés que pretende proteger, de forma que no cabe la doble punición con tipos idénticos aunque la justificación última por la que éstos se hayan dictado fuera diferente ${ }^{16}$.

En contra de esta transposición del principio non bis in idem al campo normativo se manifiesta S. DEL REY GUANTER. Este autor limita al ámbito de las sanciones el alcance del principio, que prohibiría «que un mismo hecho sea doblemente sancionado, no que sea doblemente tipificado» ${ }^{17}$. El cumplimiento del principio non bis in idem no corresponde a quien elabora y aprueba la norma, sino al que la aplica en los supuestos en que un mismo acto o hecho pueda estar tipificado y sancionado en más de un precepto punitivo $^{18}$.

Además, el principio non bis in idem no está diseñado para resolver cuál de las normas aplicables debe prevalecer: Sólo señala que resulta necesario elegir una de ellas para no dar lugar a una doble punición. Este principio no debe constituirse en criterio para determinar la validez o derogación de las normas ${ }^{19}$.

26. Dado que el principio non bis in idem está dirigido al operador jurídico y no al legislador, aquél deberá analizar si los tipos concurrentes son idénticos, en cuyo caso aplicará el principio.

De este modo, el encargado de aplicar la norma prestará atención, en primer lugar, a la existencia de uno o varios hechos y una o varias normas que los sancionen; pero sin ocuparse de los intereses protegidos en la norma que afectan básicamente al legislador. Al operador tan sólo le importan en la medida en que se vean reflejados en el tipo.

Caso de aceptar que la diferencia de intereses jurídicos protegidos por las normas justifica la aplicación de una doble sanción al mismo sujeto y por los mismos hechos, el problema del non bis in idem se trasladaría a la elección correcta de los intereses jurídicos protegidos en las normas.

Resultaría lícito, de acuerdo con esta tesis, imponer dos sanciones ante un único hecho cuando las normas que las tipifican pretenden proteger intereses diferentes.

Conforme a esta corriente de opinión, la posible acumulación de sanciones administrativas y penales depende de la idea que se tenga de la unidad o diversidad ontológica de los ilícitos y de sus sanciones. Es claro que

16 Nieto García, A., ibidem, p. 407, mantiene a este respecto que, en otro caso, se «plantearía la inquietante duda de si se trata de una justificación a posteriori inequívocamente pretextual o si, por el contrario, supone una justificación legítima».

17 Del Rey Guanter, S., Potestad sancionadora de la Administración y jurisdicción penal en el orden social, 1990, pp. 125 y 126.

18 Nieto García, A., Derecho Administrativo Sancionador, 2. a ed., Madrid, 1994, p. 405.

19 Rebollo Puig, M., Potestad sancionadora, alimentación y salud pública, 1989, p. 811. 
quienes afirman dicha unidad han de aceptar, como un corolario de ella, la prohibición del bis in idem ${ }^{20}$; mientras que quienes la niegan pueden aceptar sin graves dificultades la compatibilidad de sanciones que son diferentes por naturaleza ${ }^{21}$.

Sin embargo, si la regla del non bis in idem se invoca excesivamente ante la protección de varios intereses legalmente seleccionados, «nos encontraríamos entonces con un círculo vicioso realmente inoperante y el solemne dogma del non bis se habría disuelto al simple conjuro de una doble declaración del Legislador...» ${ }^{22}$.

27. La constatación de dos intereses protegidos agredidos eliminaría el concurso de normas; ya que las dos normas resultarán igualmente aplicables. Eliminaría igualmente de acuerdo con esta tesis la aplicación plena del principio non bis in idem; ya que se entiende que el diferente fundamento de las normas habilitantes justifica la doble punición.

Sin embargo, incluso en el caso de aceptar esta tesis, para dar una solución satisfactoria a estas situaciones podría acudirse a las normas de solución del concurso ideal o real de infracciones según los casos. Esta aplicación tendrá como consecuencia evitar la acumulación automática de las sanciones y dará lugar, dependiendo de los sistemas, a la aplicación de algunos de los criterios de atemperación de las mismas.

Veremos, al hacer referencia a la evolución vivida por el ordenamiento jurídico español, que esta tesis se encuentra actualmente superada en nuestro sistema.

\section{Requisitos del principio non bis in idem}

28. Para que la concurrencia de sanciones se considere contraria a Derecho por aplicación del non bis in idem, es necesario que se cumpla una triple identidad (ad ex., SSTS [2. ${ }^{a}$ ] de 30 enero 1981 y 3 diciembre 1991):

- Objetiva o referente a los hechos: La STS [2] de 10 noviembre 1990 entiende que no entran dentro del ámbito de protección de este principio los casos de concurso real de infracciones en que las penas se aplican por acciones diversas. La efectiva punición de un

${ }^{20}$ En este mismo sentido, ad ex., señala SuAY Rincón, J., Sanciones administrativas, Bolonia, 1989, que el alcance del non bis in idem explica la identidad sustancial entre ambos órdenes punitivos, pues si ambas sanciones no fueren de la misma causa, no podría comprenderse por qué no pueden imponerse a la vez.

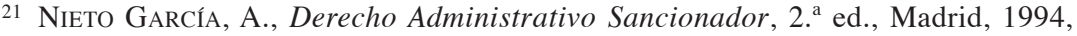
p. 402.

22 Ibidem, p. 408. 
hecho antijurídico determinado no exonera a su autor de nuevas responsabilidades si vuelve a incurrir con posterioridad en la misma conducta (STS [3. ${ }^{a}$ ] de 14 diciembre 1992;

- Subjetiva o referente al infractor: Es indiferente que el sujeto haya sido sancionado solidariamente junto con otros en el primer procedimiento y lo sea a título individual en el segundo, e igualmente es indiferente el título de culpabilidad que se esgrima contra él; y

- Causal, referente a la identidad en el fundamento punitivo. Basándose precisamente en la no coincidencia de finalidad y en la sustantividad del ilícito administrativo, la STS [2. ${ }^{a}$ ] de 30 marzo 1917, mantuvo que las atribuciones de la Administración para corregir gubernativamente las faltas no excluyen ni limitan la aplicación jurisdiccional de las disposiciones penales. La sanción administrativa no generaría cosa juzgada que excluya el proceso y la pena por los mismos hechos, porque las multas y correcciones no se considerarían penales. Esta doctrina está en la actualidad totalmente abandonada en nuestro ordenamiento jurídico.

29. Dado que la identidad en el elemento subjetivo no plantea problemas dignos de consideración en nuestro campo de estudio, procederemos a continuación a detenernos brevemente en los elementos causal y objetivo.

\section{Elemento causal}

30. Comencemos prestando atención a la exigencia de identidad en el elemento causal para que pueda considerarse aplicable el principio non bis in idem. Este elemento nos llevará a detenernos en la posible acumulación de diversas medidas que implican todas ellas restricciones de derechos.

31. Esa exigencia de identidad nos lleva a cuestionar la posible acumulación de multas ordinarias y multas coercitivas y la incidencia del non bis in idem en las relaciones entre ambos institutos.

El hecho de que las medidas coercitivas no supongan ejercicio de la potestad sancionadora de la Administración, ya que son simplemente resultado del ejercicio de la ejecución de oficio de los actos administrativos, supone que la concurrencia de éstas con medidas sancionadoras no implicará vulneración del principio non bis in idem ${ }^{23}$.

Dado que las sanciones coercitivas no tienen carácter represivo, la concurrencia de medidas punitivas con éstas, puramente coercitivas, no deberá entenderse prohibida (SSTS [4. ${ }^{\mathrm{a}}$ ] de 10 julio de 1984 y [3. ${ }^{\mathrm{a}}$ ] de 20 octubre 1984; STC 239/1988, de 14 diciembre). No pueden conceptuarse como

23 Vid., en este sentido, Lorenzo, S., Sanciones Administrativas, Uruguay, 1996. 
idénticos el hecho constitutivo de la infracción, sea cual sea, y el incumplimiento del mandato administrativo posterior; los hechos son diferentes y por ello se excluye la aplicación del principio non bis in idem: Esta concepción implica el riesgo, puesto de manifiesto por J. SUAY RINCón, de que la Administración generalice el uso de las multas coercitivas en lugar de ejercer su potestad administrativa sancionadora ${ }^{24}$. De este modo, se estaría haciendo una elusión fraudulenta del principio non bis in idem. No obstante, dada la estructura de estas sanciones no resulta realmente fácil esta sustitución; ya que, en principio, el administrado podrá evitar la imposición de las multas coercitivas, mediante la ejecución de la medida administrativa cuyo incumplimiento genera esta medida.

El hecho de que las medidas coercitivas sean restrictivas de derechos no implica que supongan ejercicio del ius puniendi. No tienen un verdadero sentido sancionador y no debe hacerse una interpretación extensiva del principio que nos ocupa: «En estas multas no se impone una obligación de pago con un fin represivo o retributivo por la realización de una conducta que se considere administrativamente ilícita, cuya adecuada previsión normativa desde las exigencias constitucionales del derecho a la legalidad en materia sancionadora pueda cuestionarse, sino que consiste en una medida de constreñimiento económico, adoptada previo el oportuno apercibimiento, reiterada en lapsos de tiempo y tendente a obtener la acomodación de un comportamiento obstativo del destinatario del acto a lo dispuesto en la decisión administrativa previa. No se inscriben, por tanto, estas multas en el ejercicio de la potestad administrativa sancionadora, sino en el de la autotutela ejecutiva de la Administración (...) no se castiga una conducta porque sea antijurídica, sino que se constriñe a la realización de una prestación o al cumplimiento de una obligación concreta previamente fijada por el acto administrativo que se trata de ejecutar, y mediante la oportuna conminación o apercibimiento» (STC 239/1988, de 14 diciembre).

32. Algo similar sucede con las medidas de seguridad; aunque la determinación de la naturaleza jurídica de éstas suele plantear más problemas que en el caso anterior.

La imposición conjunta de medidas de seguridad y penas sólo será posible cuando ambas sean de diferente naturaleza. Es decir, no puede considerarse acorde a derecho la imposición de dos consecuencias jurídicas de índole aflictiva, a cumplir sucesivamente, derivadas de un mismo y único hecho ${ }^{25}$.

${ }^{24}$ Suay Rincón, J., Sanciones administrativas, Bolonia, 1989, p. 60.

25 Queralt, J.J., El Principio non bis in idem, Madrid, 1992, pp. 25-26. El problema surge cuando tratamos de determinar si una medida concreta es en efecto aflictiva. Cabría enten- 
33. A pesar de la evidencia de la anterior afirmación, la identidad causal no suele examinarse en la naturaleza de la infracción sino en la naturaleza de los bienes jurídicos que se entienden protegidos por las normas sancionadoras. De este modo, cuando los bienes jurídicos afectados por un hecho resultan heterogéneos, se entenderá que existe diversidad de fundamento y, si son homogéneos, no procederá la doble punición ${ }^{26}$.

\section{Elemento objetivo: Unidad o pluralidad de hechos y acciones}

34. Hemos visto que uno de los requisitos que se exigen, para que pueda plantearse la aplicación del principio non bis in idem es que exista identidad de hechos; es decir, que el principio impide la reacción sancionadora múltiple del ordenamiento ante un único hecho. Por ello, resultará importante determinar cuándo el ordenamiento se enfrenta a un único hecho o, por el contrario, se plantea la reacción ante varias acciones, en cuyo caso no será de aplicación dicho principio.

der que toda privación de derechos es en sí misma aflictiva; pero el TC, en su STC 36/1991, de 4 febrero, mantiene que no toda medida restrictiva de libertad es aflictiva sino que hay que atender a su objetivo. Una medida cuya finalidad fuera educativa o terapéutica, aun cuando sea privativa de libertad, podría concurrir legítimamente con una pena. Logrado el objetivo que se pretendía con la primera medida cabría sin embargo defender el no cumplimiento de la pena por considerarla en ese punto contraproducente. No resulta tarea fácil, sin embargo, determinar cuál es la naturaleza, aflictiva o no, de las medidas de seguridad.

${ }^{26}$ La STC 234/91, de 10 diciembre, mantiene que para que la dualidad de sanciones por un mismo hecho sea constitucionalmente admisible, es necesario que la normativa que la impone pueda justificarse porque contempla los mismos hechos desde la perspectiva de un interés jurídicamente protegido que no es el mismo que aquél que la primera sanción intenta salvaguardar.

Donde esta teoría ha alcanzado su mayor provecho es en las relaciones de sujeción especial, cuyo estudio se recoge en GARBeri Llobregat, J., El Procedimiento administrativo sancionador. Comentarios, Jurisprudencia, Formularios y Legislación, Valencia, 1994, pp. 177 y ss., o Lasagabaster Herrate, I., Las Relaciones de Sujeción Especial, Madrid, 1994.

El TC, ya desde la Sentencia $2 / 1981$, fundamento jurídico $4 .^{\circ}$, admitió expresamente la coincidencia, en un mismo sujeto y para el mismo hecho, de una sanción penal y otra administrativa, cuando ésta está basada en una relación de supremacía especial. La mera pertenencia a un determinado grupo jurídico se mostraba insuficiente para explicar la reduplicación de la sanción. Por ello el mismo Tribunal, en la STC 61/1990, de 29 marzo, dotó al bis in idem constitucionalmente permitido de una fundamentación material. Partiendo de la exigencia de identidad en objeto, sujeto y fundamento, la STC 2/81 mantenía que en las relaciones especiales de poder, es decir en las sanciones disciplinarias, no existe identidad de fundamento, en la medida en que el ordenamiento penal y el disciplinario protegen bienes distintos y se afectan por tanto bienes jurídicos dispares. El fundamento de la sanción disciplinaria es, sin embargo, igual que el de la penal, el mantenimiento de la capacidad de prestación de servicios públicos. Este hecho, junto con la evidente consideración de que con la admisión de la doble sanción se debilita el principio de legalidad, han dado lugar a que el propio TC en Sentencias como la 234/1991, de 10 diciembre, module, aunque sin excluirla, la aceptación del bis in idem dentro del ámbito disciplinario. 
35. Para determinar la existencia de uno o varios hechos, hay que tener en cuenta que una acción puede estar constituida por una pluralidad de actos, sin que por ello se desvirtúe su carácter unitario, dada la especial vinculación existente entre ellos.

Ante esta situación, habrá que fijar unos criterios que nos ayuden a determinar cuándo un grupo de actos aislados puede considerarse de forma unitaria y cuándo, por el contrario, pueden ser disgregados e integrar acciones independientes.

A pesar de que esta simplificación no puede llevarnos a desconocer el hecho de que existe una acalorada controversia doctrinal respecto de lo que debe entenderse por identidad de hecho, dos son las principales opciones que se presentan al operador jurídico para realizar dicha determinación ${ }^{27}$.

36. De acuerdo con un primer criterio, el hecho se califica, conforme a su percepción física o natural. Se considera, de este modo, un hecho único el que responde a un solo acto de voluntad. Como tal, se realiza en la vida y se percibe por el sujeto actor y los terceros. Esta teoría atiende exclusivamente a datos naturalísticos para determinar la existencia de una o varias acciones ${ }^{28}$. Lo normal, de acuerdo con la concepción general de la vida, es que sea la «voluntad convergente de un telos inmediato la que dote de unidad natural a la acción que, al quedar recortada por un mismo tipo penal, da lugar a un solo delito» (STS [2. $\left.{ }^{\mathrm{a}}\right]$ de 12 diciembre 1977).

La unidad de acción delictiva exige que, desde el punto de vista subjetivo, concurra un único acto de voluntad encaminado a la realización de toda la dinámica delictiva (STS [2. ${ }^{\circledR}$ ] de 26 junio 1983). Como elementos objetivos de esta actividad, puede exigirse que todos los actos estén vinculados espacial y temporalmente; porque la disgregación de la dinámica delictiva en uno y otro sentido puede romper la identidad que reclama la voluntad única.

El concepto de hecho será, por lo tanto, valorativo. En este sentido, depende de una determinada valoración según la cual varios movimientos deben contemplarse como una sola acción.

No existe unanimidad doctrinal sobre el que debería ser el punto de vista que decide cual es la valoración; aunque un criterio podría ser la concepción

27 Un reflejo de las principales corrientes doctrinales italianas y alemanas con sus diversos matices y las críticas más comunes vertidas a raíz de cada una de ellas puede encontrarse en García Albero, R., Non bis in idem Material y Concurso de Leyes Penales, Barcelona, 1995 , pp. 143 y ss.

28 Esta teoría es generalmente descartada por la doctrina, tal como recoge MiR Puig, S., Derecho Penal. Parte General, Barcelona, 1995, p. 653, ya que «ni es posible buscar una clara solución de continuidad a los movimientos fisiológicos, ni éste es el punto de vista que utilizamos normalmente para afirmar que existen una o varias acciones». 
natural de la vida. Según ésta, se confía al punto de vista de la sociedad o a los usos normales la valoración de cuándo varios movimientos corresponden a una acción. Se atiende a la unidad de propósito y a la conexión de los diversos hechos integrantes de la acción en el espacio y en el tiempo.

37. El otro criterio posible para determinar la unidad de hecho es aquél que atiende a la óptica normativa, y exige que se dé la identificación en la tipología delictiva. De acuerdo con el mismo se califican los hechos como unidad o pluralidad, no atendiendo a la naturaleza de la percepción natural del observador ni a la voluntad de quien actúa, sino precisamente, de acuerdo con la voluntad del legislador que se contiene en el tipo correspondiente ${ }^{29}$.

Esto no supone que siempre que exista unidad de hecho deba concurrir un solo tipo y un solo delito; pero sería la norma quien nos diga, en cada caso, si median uno o varios hechos. Ella tendría poder para, a efectos sancionadores, reunir varios hechos naturales en un solo tipo o, a la inversa, descomponer un solo hecho natural en varios tipos ${ }^{30}$.

Prescindiendo de los hechos naturales y ateniéndonos a los tipos normativos, el problema se simplifica; porque la solución a cada caso puede encontrarse en los elementos que la norma ha seleccionado a la hora de tipificar la acción. De acuerdo con esta tesis, al hilo de un solo hecho natural puede haber varias acciones, varios tipos y varias infracciones. Por ello, no entraría en juego la prohibición del principio non bis in idem y únicamente cabría establecer modalidades en la atribución de las penas por considerar que se trata de un concurso real o medial.

\section{Dinámica de la regla}

38. La regla que estamos examinando tiene - como en parte podría colegirse de lo que se ha expuesto hasta ahora - dos vertientes:

a) Una vertiente procesal - o ex ante - busca eliminar la posibilidad de que un único hecho antijurídico sea simultáneamente enjuiciado en dos procedimientos.

b) Otra vertiente material - o ex post - hace referencia a la prohibición de la doble sanción, siempre, evidentemente, hablando de un solo y único hecho, y ante la identidad de sujetos y fundamento.

29 Mir PUIG, S., Ibidem, p. 654, mantiene que «la descripción típica opera, pues, como una plantilla que recorta un determinado fragmento de actividad humana y permite considerarla constitutiva de una unidad de hecho».

30 Nieto García, A., Derecho Administrativo Sancionador, 2. ${ }^{a}$ ed., Madrid, 1994, pp. 449 y 450. 
Para evitar la posibilidad de esta doble concurrencia, el ordenamiento se ve obligado a reaccionar, si bien cabe adoptar diversas soluciones.

39. La aplicación del principio de que nos ocupamos ante la reacción represiva del Estado dentro de un único sector del ordenamiento no plantea problemas teóricos: No plantea excesivas dificultades aceptar el hecho de que no pueden imponerse dos sanciones penales o dos sanciones administrativas ante la comisión de un único hecho. Aunque con algunas excepciones de las que nos ocuparemos más adelante, este principio es admitido por la mayoría de los ordenamientos jurídicos de nuestro entorno.

40. Mayores dificultades plantea la acumulación extraordinamental de procedimientos y sanciones. Por ello, nos centraremos fundamentalmente en los problemas derivados de la acumulación de sanciones y procedimientos administrativos y penales.

\section{La vertiente material del principio}

41. Comencemos prestando atención al aspecto material del principio - es decir, a la prohibición de que existan dos sanciones ante una única acción-.

Hemos visto que, de acuerdo con este principio, no resulta admisible la doble represión por el mismo hecho: En caso de que, de forma indebida, se hayan pronunciado dos sanciones, una de ellas debería declarase inválida.

Más complejo será determinar cuál de ellas debe anularse, sobre todo en el caso de que nos encontremos con sanciones provenientes de diferentes ordenamientos y, por lo tanto, de naturaleza jurídica diversa.

Ante este dilema, centrándonos en la acumulación de una sanción penal y una administrativa, cabe optar por la prevalencia de la sanción penal, manteniendo que es aplicable el principio non bis in idem, como resueltamente ha hecho la jurisprudencia española ${ }^{31}$.

La razón de ser de esta solución se encontraría en la presunción de que la jurisdicción penal es la que mejor garantiza los derechos y libertades individuales frente a la actitud menos garantista del poder ejecutivo. No quedaría claro, sin embargo, con la citada explicación, qué sucedería en el caso de que sea la sanción administrativa la que haya sido impuesta con anterioridad.

31 Sirva como muestra la STS 20 octubre 1984 y, en el mismo sentido, la STC 77/83, de 3 octubre, que mantiene que «la subordinación de los actos de la Administración de imposición de sanciones a la autonomía judicial exige que la colisión entre una actuación jurisdiccional y una actuación administrativa haya de resolverse en favor de la primera». 
Frente a esta opción, cabría adoptar un criterio cronológico, según el cual la primera decisión condenatoria vetaría la existencia de la segunda, independientemente de cuál sea la autoridad que haya impuesto la primera. Esta es la opción adoptada por la legislación italiana. El TS español ha mantenido esta tesis en alguna resolución, si bien de forma mucho más esporádica que la tesis inspirada en criterios materiales ${ }^{32}$.

\section{La vertiente procesal del principio}

42. Dentro de la dinámica de funcionamiento del principio non bis in idem en su vertiente procesal, veíamos que el Derecho debe arbitrar unos mecanismos para evitar la concurrencia de procedimientos. De esta forma, cabría realizar una mezcla de los criterios de prevalencia anteriormente expuestos, el material y el cronológico, estableciendo por ley un mecanismo procesal, consistente en conseguir por razones materiales, la prioridad cronológica de la sentencia penal. Así, entendiendo que el efecto material del principio no es razón suficiente para realizar la asignación de prevalencias, se impide a la Administración actuar hasta tanto no lo hayan hecho los tribunales.

De hecho, asegurar la prioridad cronológica de la sentencia penal es una posibilidad de imponer la prevalencia de la sentencia penal; ya que, una vez producida la resolución administrativa sancionadora, sería muy difícil hacer viable «hacia atrás» la influencia de una sanción penal posterior ${ }^{33}$.

Para evitar esta situación, se declara la prioridad del proceso penal y la «imposibilidad de que los órganos de la Administración lleven a cabo actuaciones o procedimientos sancionadores en aquellos casos en que los hechos puedan ser constitutivos de delito o falta según el Código Penal o las leyes especiales, mientras la autoridad judicial no se haya pronunciado sobre ellos» (STC 77/1983, de 3 de octubre, que se reproduce en la STS 20 enero 1987).

No en vano «...cuando se da identidad de hechos del procedimiento administrativo sancionador y del proceso penal, se hace necesario el mejor esclarecimiento de los hechos (...) que se obtendrá de las declaraciones de hechos probados y de las consideraciones que haya de contener la resolución del proceso criminal instruido. De aquí que lo más acorde con el ordenamiento jurídico sea el declarar en suspenso el procedimiento admi-

32 Así, en la STS [2. $\left.{ }^{a}\right] 12$ mayo 1986, se recoge que «el principio de Derecho non bis in idem no permite, por unos mismos hechos, duplicar o multiplicar la sanción sea cual sea la autoridad que primeramente la haya impuesto...».

33 En opinión de Nieto García, A., Derecho Administrativo Sancionador, 2. ${ }^{\text {a }}$ ed., Madrid, 1994, p. 424, la única posible. 
nistrativo hasta tanto no recaiga resolución firme en el proceso penal» (STS 18 diciembre 1989; en el mismo sentido, STS 24 enero de 1989).

43. Sobre la declaración de hechos probados se establece igualmente, desde el momento en que se reconoce la vigencia del principio non bis in idem, la prevalencia de la sentencia penal de forma que la redacción de los hechos establecida por la sentencia penal vincula a la autoridad administrativa ${ }^{34}$.

Esta situación no ha sido siempre tal como, en este momento. se describe. La STS 21 febrero 1979, mantiene que ha existido en nuestra jurisprudencia una arraigada doctrina que mantenía que el resultado de las actuaciones sumariales «carecen de todo efecto vinculatorio» en la actuación administrativa respecto del ejercicio de sus facultades sancionadoras, incluso en el caso de que, en la sentencia penal, se hayan declarado probados los hechos. Ello se debería a que la «valoración realizada por esa jurisdicción opera con técnicas y criterios diversos a los que sobre los mismos hechos han de servir de fundamento a los que por la jurisdicción contenciosa se dicte».

44. En los casos en que el ordenamiento jurídico permite que se mantengan dos procedimientos por los mismos hechos, uno de carácter administrativo y otro de carácter penal, sería inconstitucional la fijación fáctica diversa. Expresado con otros términos, unos hechos no pueden existir para unos órganos del Estado y dejar de existir para otros: La STC 77/83, de 3 octubre, afirma de modo contundente que «es inconstitucional un doble castigo penal y administrativo por un mismo hecho; y no sólo eso sino que la jurisdicción penal es preferente sobre la gubernativa en orden al esclarecimiento de los hechos» ${ }^{35}$. Por ello, la Administración debe paralizar el procedimiento en tanto que los jueces ordinarios no decidan sobre el fondo y, en el caso de que la jurisdicción penal declare la inexistencia del hecho ilícito, deberá aceptar tal declaración y archivar, consecuentemente lo actuado.

34 Un examen detallado de las diferentes consecuencias que tiene la sentencia penal en las actuaciones posteriores según sea ésta absolutoria o condenatoria, puede encontrarse en NIETO García, A., Derecho Administrativo Sancionador, 2. ${ }^{a}$ ed., Madrid, 1994, pp. 429-435.

35 En el mismo sentido mantiene LóPez Nieto Mayo, F., El Procedimiento Administrativo de las Administraciones Públicas, Barcelona, 1993, p. 544, que, cuando el ordenamiento permite dualidad de procedimientos, es posible enjuiciamiento y calificación jurídica independiente de los mismos hechos, pero no sucede lo mismo en lo referido a la apreciación de dichos hechos, que no pueden existir y dejar de existir al mismo tiempo. Si se considera la subordinación de la potestad sancionadora de la Administración a la actuación de los tribunales de justicia, la conclusión es que aquélla no puede actuar en materia de sanciones mientras no lo hayan hecho los tribunales, y, cuando intervenga a posteriori, debe respetar en todo caso el relato de los hechos realizado por estos últimos. 
45. El problema del non bis in idem en la coincidencia extraordinamental, se traslada al ámbito administrativo, siendo en el curso de este procedimiento y no en el penal en el que se alegará la excepción. En el supuesto de que, impuesta una sanción administrativa, se inicie un proceso penal basado en los mismos hechos, la sanción administrativa deberá quedar automáticamente en suspenso ${ }^{36}$.

Nuestro TC, sentada la doctrina de que «en la realidad jurídica, esto es, en la realidad histórica relevante para el Derecho, no puede admitirse que algo es y no es, que unos mismos hechos ocurrieron y no ocurrieron» admite, sin embargo, que unos mismos hechos puedan producir efectos jurídicos distintos (STC 25/1984, de 23 febrero). Por ello, sería posible que, de producirse la absolución en la sentencia penal, por no haberse demostrado la autoría del imputado, la sanción administrativa aprecie una responsabilidad distinta en el sujeto.

\section{El principio non bis in idem en Derecho europeo de la competencia}

\section{Concepto y naturaleza jurídica}

46. El concepto de non bis in idem en Derecho comunitario no es diferente al de los Derechos nacionales: «El citado principio prohíbe... sancionar a una misma persona más de una vez por un mismo comportamiento ilícito con el fin de proteger el mismo bien jurídico» (STJCE 7 enero 2004, Aalborg Portland A/S, Irish Cement Ltd, Ciments français SA, Italcementi - Fabbriche Riunite Cemento SpA, Buzzi Unicem SpA y Cementir - Cementerie del Tirreno SpA, C-204/00 P, C-205/00 P, C-211/00 P, C-213/00 P, C-217/00 P y C-219/00 P, apartado 338) $)^{37}$.

${ }^{36}$ En el caso de que la sanción administrativa haya devenido firme, no existirá vía procesal para resolver la cuestión, pero QUERALT, J.J., El Principio non bis in idem, Madrid, 1992, p. 32, mantiene la supremacía de la doctrina constitucional sobre la ley, de forma que el juez penal debería requerir de inhibición a la autoridad administrativa «en el concreto sentido de que por ésta se acuerde la suspensión de la ejecución de la sanción»; caso de que la sanción haya sido recurrida ante la jurisdicción contencioso-administrativa, sí existirán mecanismos procesales para paralizar la tramitación de la causa contenciosa hasta que finalice la penal.

37 Vid., ad ex., EILMANSBERGER, T., «Ne bis in idem und die Zuständigkeitsverteilung im Netzwerk der Wettbewerbsbehörden», en KöcK, H.F. (Hrsg.), Europarecht im Zeitalter der Globalisierung. Festschrift für Peter Fischer, Wien, 2004, pp. 33-51; ID., «'Ne bis in idem' und kartellrechtliche Drittstaatssanktionen. Zugleich Besprechung des EuG-Urteils vom 9.7.2003 - Rs. T.224/00, Archer Daniels Midland Company (ADM)», EWS, 15, 2, 2004, pp. 49-55; Gauer, C./Paulis, E., «Le règlement n. ${ }^{\circ} 1 / 2003$ et le principe du ne bis in idem», Concurrences, n. ${ }^{\circ}$ 1, 2005, pp. 32-40; E. VergnANo, «Competenze parallele e ne bis in idem: principi concorrenti nella nuova regolamentazione antitrust», Diritto pubblico comparato ed europeo, 2005, III, pp. 1429-1447; W.P.J. WILS, «The principle of "ne bis in 
47. Según la jurisprudencia comunitaria, el principio non bis in idem, consagrado igualmente en el art. 4 del Protocolo n. ${ }^{\circ} 7$ del CEDH, constituye un principio fundamental del Derecho comunitario, cuya observancia debe garantizar el juez (STJCE 5 mayo 1966, Gutmann/Comisión, 18/65 y 35/65, Rec., pp. 149 ss., concr. p. 172; STJCE 14 diciembre 1972, Boheringer Manheim GmbH/Commission, 7/72, Rec., p. 1281, apartado 3; STPI 20 abril 1999, Limburgse Vinyl Maatschappij y otros/Comisión, T-305/94 a T-307/94, T-313/94 a T-316/94, T-318/94, T-325/94, T-328/94, T-329/94 y T-335/94, Rec., p. II-931, apartado 96, confirmada, en este apartado, por la STJCE 15 octubre 2002, Limburgse Vinyl Maatschappij y otros/Comisión, C-238/99 P, C-244/99 P, C-245/99 P, C-247/99 P, C-250/99 P a C-252/99 P y C-254/99 P, Rec., p. I-8375, apartado 59; STPI 29 abril 2004, Tokai Carbon y otros/Comisión, T-236/01, T-239/01, T-244/01 a T-246/01, apartado 130) y cuya aplicación está supeditada a un triple requisito de identidad de los hechos, unidad de infractor y unidad de interés jurídico protegido (STJCE 7 enero 2004, Aalborg Portland A/S, Irish Cement Ltd, Ciments français SA, Italcementi - Fabbriche Riunite Cemento SpA, Buzzi Unicem SpA y Cementir - Cementerie del Tirreno SpA, C-204/00 P, C-205/00 P, C-211/00 P, C-213/00 P, C-217/00 P y C-219/00 P, apartado 338). No es extraño, pues, que también haya sido acogido por el art. 50 de la Carta de los Derechos Fundamentales de la UE (DO C 364 de 18 diciembre 2000) ni que algunos autores consideren que ya el art. 45 del Convenio de Schengen de 1990 representa el primer intento multilateral para establecer dicho principio que ha tenido éxito ${ }^{38}$.

48. En el ámbito del Derecho de la competencia comunitario, dicho principio prohíbe que se condene a una empresa o que la Comisión inicie de nuevo un procedimiento sancionador en su contra por un comportamiento contrario a la competencia a causa del cual ya ha sido sancionada o del que la Comisión la ha declarado no responsable mediante una decisión anterior que ya no puede ser objeto de recurso (STPI 9 julio 2003, Archer Daniels Midland Company y Archer Daniels Midland Ingredients Ltd/Comisión, T-224/00, apartado 86).

idem" in EC antitrust enforcement: a legal and economic analysis», World Compet., 26, 2, 2003, pp. 131-148.

38 VAn Den Wyngaert, C./Stessens, G., «The international non bis in idem principle: resolving some of the unanswered questions», Int.Comp.L.Q., 48, 4, 1999, pp. 779-804, concr. p. 804. Para un análisis más detallado de este precepto, vid. DonaIRE Villa, F.J., «Transacción penal y principio ne bis in idem en el espacio de libertad, seguridad y justicia: la interpretación del artículo 54 del Convenio de Schengen (Comentario a la primera Sentencia prejudicial del TJCE ex art. 35 del TUE, de 11 de febrero de 2003, Asuntos Acumulados C-187/01 y C-385/01, Gözütok/Brügge)», Revista española de Derecho Europeo, 7, julioseptiembre 2003, pp. 571-594. 
49. Según la jurisprudencia del Tribunal Europeo de Derechos Humanos, los procedimientos administrativos son equiparables, a efectos del art. 6.1 de la Convención Europea de Derechos Humanos, a los procesos penales, cuando aquéllos son susceptibles de conducir a la imposición de sanciones importantes a personas físicas (CEDH, 21 febrero 1984, Öztürk, n. ${ }^{\circ} 8544 / 79$, Serie A, n. ${ }^{\circ}$ 73; CEDH, 24 febrero 1994, Bendenoun, n. ${ }^{\circ}$ 12547/86, Serie A, n. $\left.{ }^{\circ} 284\right)$. No es difícil extrapolar esta jurisprudencia ni a las personas jurídicas ni al Derecho de la competencia ${ }^{39}$.

50. El principio non bis in idem contribuye a la aplicación eficiente del Derecho europeo de la competencia: favorece la imposición de la sanción óptima con el mínimo coste (= lucha contra sanciones excesivas o livianas [over-punishment and under-punishment]), evita el coste de procedimientos múltiples, fomenta una persecución eficiente, reduce el riesgo de enojosos procedimientos múltiples y crea incentivos para una eficiente coordinación entre los demandantes (W.P.J. WILS) ${ }^{40}$.

\section{Origen}

51. El TJCE tuvo la oportunidad de tomar partido sobre el principio non bis in idem en el caso conocido como Walt Wilhelm (STJCE 13 febrero 1969, Farbenfabrik Bayer AG et autres/Bundeskartellamt, Berlin, 14/68, Rec., p. 1). El Bundeskartellamt había sancionado con multas importantes a siete empresas alemanas productoras de materias colorantes - una de las cuales era la Farbenfabrik Bayer AG, de cuyo director toma el nombre con que se conoce esta decisión judicial-, cuatro de las cuales estaban implicadas en el procedimiento que contra ellas - y también contra empresas de otros Estados - había incoado la Comisión en el caso conocido como asunto de las materias colorantes (vid. Dec. Com. 24 julio 1969, Matiéres colorantes, JOCE L 195 de 7 agosto 1969, que fue confirmada por STJCE 14 julio 1972, Badische Anilin- und Soda-Fabrik AG, Farbenfabriken Bayer $A G, J . R$. Geigy AG, Sandoz AG, S.A., française des matiéres colorantes [(Francolor], Casella Farbwerke Mainkur AG, Farbewerke Hoechst AG, Azienda Colori Nazionali/Commission, 49-69 y 51 a 57/69, Rec., p. 713). El

39 Nadie en la doctrina discute que las personas jurídicas puedan ser titulares de derechos fundamentales ni que las empresas entren en el ámbito personal de aplicación (persönlicher Anwendungsbereich) del principio non bis in idem. Vid., per omnia, EILMANSBERGER, T., «Ne bis in idem und die Zuständigkeitsverteilung im Netzwerk der Wettbewerbsbehörden», en KöcK, H.F. (Hrsg.), Europarecht im Zeitalter der Globalisierung. Festschrift für Peter Fischer, Wien, 2004, p. 43.

${ }^{40}$ WILS, W.P.J., «The principle of "ne bis in idem" in EC antitrust enforcement: a legal and economic analysis», World Compet., 26, 2, 2003, pp. 136-140. 
Kammergericht Kartellsenat de Berlín Oeste planteó un recurso, en aplicación del art. 234 TCE (antiguo art. 177 TCEE), tendente a obtener una decisión a título prejudicial sobre interpretación de los arts. 5, 7 y 81 del Tratado de Roma y 9 del Reglamento del Consejo n. ${ }^{\circ} 17$.

52. En su sentencia, el Tribunal recurrió, como reglas de base para resolver los conflictos entre el Derecho comunitario y los ordenamientos jurídicos nacionales de los Estados integrantes de la Comunidad, a los principios de:

a) Superioridad del Derecho comunitario, principio que había sido formulado ya anteriormente: «El TCEE ha instituido un orden jurídico propio, integrado en el sistema jurídico de los Estados miembros y que se impone a sus jurisdicciones.

Sería contrario a la naturaleza de tal sistema admitir que los Estados miembros puedan tomar o mantener en vigor medidas susceptibles de comprometer el efecto útil del Tratado.

La fuerza imperativa del Tratado y de los actos adoptados para su aplicación no debería variar de un Estado a otro por el efecto de los actos internos, sin que sea entorpecido el funcionamiento del sistema comunitario y puesta en peligro la realización de los fines del Tratado. Desde entonces, los conflictos entre la regla comunitaria y las reglas nacionales deben ser resueltos por la aplicación del principio de la primacía de la regla comunitaria».

b) Y de aplicación paralela de los supuestos de hecho - principio que se hace eco de la teoría de la doble barrera- o, lo que es lo mismo, del eventual concurso de procedimientos paralelos por parte de las autoridades comunitarias y nacionales con base respectivamente en el Tratado y en su ordenamiento nacional, aunque esto signifique la aplicación simultánea de ambos ordenamientos a un mismo supuesto y, por consiguiente, la posibilidad de que se dicte una doble sanción: «En tanto que un reglamento adoptado en virtud del art. 87.2.e) del Tratado no haya dispuesto de otra manera, las autoridades nacionales pueden intervenir contra una entente, en aplicación de su Derecho interno de la competencia, incluso cuando el examen de esta entente desde el punto de vista del Derecho comunitario está pendiente ante la Comisión...».

53. Además, el Tribunal formuló otros dos principios complementarios de este último: el principio de aplicación uniforme del Derecho comunitario y la regla non bis in idem - que el Tribunal consideró que no era aplicable al caso, porque los dos Derechos, el nacional y el comunitario, protegían intereses jurídicos distintos-. 
Además, el Tribunal señaló el deber, por parte de la Comisión, cuando deba sancionar un comportamiento colusorio, de tener en cuenta las sanciones que ya hayan sido impuestas por las autoridades nacionales en aplicación de su propio ordenamiento jurídico: «...bajo reserva sin embargo de que esta ejecución del Derecho nacional no pueda suponer un perjuicio a la aplicación plena y uniforme del Derecho comunitario y al efecto de los actos de ejecución de éste. Si la existencia de procedimientos paralelos debe conducir a un cúmulo de sanciones, una exigencia general de equidad implica que se tenga cuenta de toda decisión represiva anterior para la determinación de una eventual sanción».

54. Algunos autores han sostenido que la jurisprudencia Walt Wilhelm es contraria a la del Tribunal Europeo de Derechos Humanos que aplica el principio non bis in idem cuando ambos ilícitos contiene los mismos elementos esenciales (CEDH 29 mayo 2001, Franz Fischer/Austria, n. $\left.{ }^{\circ} 37950 / 97\right)^{41}$. Incluso, en un caso, el Abogado general D. RUIZ-JARABO COLOMER ha sostenido, enfrentándose a dicha jurisprudencia, que tanto el Derecho comunitario como el nacional persiguen el mismo fin (la protección de la competencia en el interior de la UE) (Opinión de D. RUIZ-JARABO COLOMER de 11 febrero 2003, apartado 91, en el caso resuelto por STJCE 7 enero 2004, Italcementi Spa, C-213/00 P) ${ }^{42}$.

\section{Dobles sanciones en virtud del Derecho comunitario}

55. El principio comunitario de non bis in idem es aplicable a las multas impuestas a los comportamientos colusorios, aunque carezcan de naturaleza penal ${ }^{43}$. En consecuencia, no se puede iniciar un nuevo procedimiento o sancionar otra vez a una empresa que ya ha sido sometida a un procedimiento por causa de un comportamiento colusorio que acabó con la imposición de una sanción que ya no es recurrible o con la declaración de no responsabilidad de la misma (STJCE 15 octubre 2002, Limburgse Vinyl Maatschappij y otros/Comisión, C-238/99 P, C-244/99 P, C-245/99 P, C-247/99 P, C-250/99 P a C-252/99 P y C-254/99 P, Rec., p. I-8375, apartado 61).

56. La anterior afirmación tiene un límite: Cuando una primera decisión haya sido anulada por motivos formales, sin pronunciarse sobre los aspectos

41 Vid., ad ex., WILS, W.P.J., «The principle of "ne bis in idem" in EC antitrust enforcement: a legal and economic analysis», World Compet., 26, 2, 2003, p. 143.

${ }^{42}$ En términos muy parecidos, se expresó con anterioridad KUCK, T., «Die Anerkennung des Grundsatzes ne bis in idem im europäischen Kartellrecht und seine Anwedung in internationalen Kartellverfahren», WuW, 52, 7-8, pp. 689-698, concr. pp. 693-694.

43 En este sentido, ad ex., Mestmäcker, E.-J./Schweizer, H., Europäisches Wettbewerbsrecht, München, 2004, p. 509. 
materiales del caso, podrán imponerse nuevas sanciones; puesto que éstas no se acumulan a las pronunciadas por la decisión anulada, sino que las sustituyen (STJCE 15 octubre 2002, Limburgse Vinyl Maatschappij y otros/Comisión, C-238/99 P, C-244/99 P, C-245/99 P, C-247/99 P, C-250/99 P a C-252/99 P y C-254/99 P, Rec., p. I-8375, apartados 59 a 63).

57. Por el contrario, el principio non bis in idem se opondría a una segunda decisión, cuando la primera haya sido anulada no por motivos procedimentales, sino por falta de pruebas (STJCE 15 octubre 2002, Limburgse Vinyl Maatschappij y otros/Comisión, C-238/99 P, C-244/99 P, C-245/99 P, C-247/99 P, C-250/99 P a C-252/99 P y C-254/99 P, Rec., p. I-8375, apartados 68 y 69). Se exceptuaría el caso de que el nuevo procedimiento se abra con base en hechos descubiertos con posterioridad, distintos de aquellos en los que se basó la anterior decisión (art. 4.2 del Protocolo n. ${ }^{\circ} 7$ de Convenio Europeo de Derechos Humanos; art. 9.2, letra a], del Reglamento 1/2003) (W.P.J. WILS) ${ }^{44}$.

\section{Dobles sanciones en relación a las sanciones de los Estados miembros}

58. La jurisprudencia comunitaria ha acogido el principio non bis in idem en los términos anteriormente expuestos, cuando la Comisión ha conocido de comportamientos colusorios que habían sido anteriormente sancionados por autoridades de un Estado miembro - ad ex., alemanas (STJCE 14 julio 1972, Badische Anilin- und Soda-Fabrik AG, Farbenfabriken Bayer AG, J. R. Geigy AG, Sandoz AG, S.A., française des matiéres colorantes [(Francolor], Casella Farbwerke Mainkur AG, Farbewerke Hoechst AG, Azienda Colori Nazionali/Commission, 49-69 y 51 a 57/69, Rec., p. 713) o francesas (STPI 6 abril 1995, Trefileurope y otros, T-141/89 y ss., Rec., p. II-791 ss.)-.

Además, la jurisprudencia ha admitido la posibilidad de acumulación de sanciones, una comunitaria y otra nacional, como resultado de la existencia de dos procedimientos paralelos (Verfahrenshäufung), que persiguen objetivos distintos, cuya procedencia resulta del especial sistema de reparto de competencia entre la Comunidad y los Estados miembros en materia de competencia (= doble imputación de responsabilidad, en el ámbito comunitario y en el ámbito nacional).

No obstante, una exigencia general de equidad implica que, al fijar la cuantía de la multa, la Comisión está obligada a tener en cuenta las sanciones que ya se han impuesto a la misma empresa por el mismo hecho (Anrechnungsprinzip), si se trata de sanciones impuestas por infracciones al Dere-

44 WILS, W.P.J., «The principle of "ne bis in idem" in EC antitrust enforcement: a legal and economic analysis», World Compet., 26, 2, 2003, pp. 141-142. 
cho de la competencia de un Estado miembro y, por consiguiente, cometidas en territorio comunitario (STJCE 13 febrero 1969, Wilhelm y otros, Rec., p. 1, apartado 11; STJCE 14 diciembre 1972, Boheringer Manheim GmbH/ Commission, 7/72, Rec., p. 1281, apartado 3; STPI 6 abril 1995, Tréfileurope/Comisión, T-141/89, Rec., p. II-791, apartado 191; STPI 6 abril 1995, Sotralentz/Comisión, T-149/89, Rec., p. II-1127, apartado 29); STPI 29 de abril de 2004, Tokai carbón Co. Ltd y otros/Comisión de las Comunidades Europeas As. T-236/01, T-239/01, T-244/01, T-245/01, T-246/01, T-251/01 y T-252/01 ; STPI 15 junio 2005, Graphites spéciaux, T-71/03, T-74/03, T-87/03 y T-91/03 ${ }^{45}$.

\section{Dobles sanciones en relación a terceros Estados}

59. Pero la propia jurisprudencia comunitaria no ha sido tan generosa ni firme con las sanciones de autoridades administrativas cuando éstas pertenecen a terceros Estados.

Así, la STJCE 14 diciembre 1972, Boheringer Manheim GmbH/Commission, 7/72, Rec., p. 1281, mantuvo, como principio, la misma solución de equidad para la hipótesis de que la sanción ya recaída proceda de un Estado no integrado en la $\mathrm{CE}$, si bien subordinándola a una condición que - dado el carácter territorial de la competencia ejercida en este tipo de asuntos por los órganos administrativos - es difícil que concurra y, por lo tanto, que se pueda extrapolar la solución del primer supuesto a éste: «Fijando el importe de una multa, la Comisión está obligada a tener cuenta de las sanciones que habrían sido ya soportadas por la misma empresa por el mismo hecho, cuando se trata de sanciones infligidas por infracción del Derecho de ententes de un Estado miembro y, por consiguiente, cometidas sobre el territorio comunitario. La toma en consideración eventual por la Comisión de una sanción infligida por las autoridades de un tercer Estado presupone que los hechos considerados contra la empresa inculpada por la Comisión por una parte y las autoridades del tercer Estado, por otra parte, sean idénticos».

No cabe, pues, extrañarse de que la STPI 9 julio 2003, Archer Daniels Midland Company y Archer Daniels Midland Ingredients Ltd/Comisión, T-224/00, apartados 85 a 104, considerase que el principio non bis in idem no podía aplicarse al caso en cuestión, puesto que los procedimientos de-

${ }^{45}$ Así, ad ex., el TPI recordó, de acuerdo con la jurisprudencia Walt Wilhem y Boheringer, la necesidad de tomar en consideración las sanciones anteriormente impuestas en un supuesto en el que empresas alemanas constituyeron un cártel de crisis, que duró de 1983 a 1988, cártel que, por un lado, fue autorizado por el Bundeskartellamt y, por otro, sancionado tanto por la Commission de la concurrence francesa como por la propia Comisión (STPI 6 abril 1995, Trefileurope y otros, T-141/89 y ss., Rec., p. II-791 ss. 
sarrollados y las sanciones impuestas por la Comisión, por una parte, y por las autoridades de un tercer Estado (Estados Unidos), por otra, no perseguían los mismos objetivos ${ }^{46}$.

La STPI 29 abril 2004, Tokai Carbon y otros/Comisión, T-236/01, T-239/01, T-244/01 a T-246/01, apartado 123, declara, siguiendo esta misma línea jurisprudencial, que, si la Comisión hubiera debido deducir el importe de la multa impuesta por las autoridades estadounidenses a una de las empresas (SGL), no hubiera podido sancionar la infracción del art. $81 \mathrm{TCE}$, puesto que alcanzaba ya el límite del 10\% de la cifra de negocios mundial de esa empresa.

\section{El Reglamento 1/2003}

60. Desde 1 mayo 2004, es aplicable el Reglamento 1/2003, que sustituye al célebre Reglamento $n .^{\circ} 17$. Dicho reglamento guarda silencio sobre el principio non bis in idem. Cabe preguntarse, por tanto, si dicho principio

46 La lisina es el principal aminoácido utilizado en la alimentación animal con fines nutricionales. La lisina sintética se emplea como aditivo en alimentos que no contienen suficiente lisina natural, por ejemplo, los cereales, para permitir a los especialistas en nutrición la creación de regímenes a base de proteínas que respondan a las necesidades alimenticias de los animales.

En 1995, tras una investigación secreta llevada a cabo por el Federal Bureau of Investigation (FBI), se efectuaron registros en Estados Unidos en los locales de varias empresas presentes en el mercado de la lisina. En agosto y octubre 1996, las sociedades Archer Daniels Midland, Kyowa Hakko Kogyo, Sewon, Cheil Jedang y Ajinomoto fueron acusadas por las autoridades americanas por haber concluido un cártel de fijación de precios de la lisina y de reparto de los volúmenes de venta de dicho producto entre junio 1992 y junio 1995.

En julio 1996, Ajinomoto propuso a la Comisión europea cooperar con ella para demostrar la existencia de un cártel en el mercado de la lisina y sus efectos en el EEE. Efectivamente, en junio 2000, la Comisión consideró probada la existencia de una serie de acuerdos que cubrían el conjunto del EEE y que se referían a los precios, volúmenes de ventas y al intercambio de informaciones individuales sobre los volúmenes de ventas de lisina sintética para el período de julio 1990 a junio 1995. La Comisión impuso a las sociedades participantes en el cártel multas por un importe global de alrededor de 110 millones de euros.

En sus recursos ante el TPI, dos de las sociedades invocaron el hecho de que ellas ya habían sido sancionadas en los Estados Unidos por su participación en este mismo cártel mundial y que la Comisión no lo había tenido en cuenta. El TPI consideró que el principio non bis in idem, según el cual una persona ya juzgada no puede ya ser perseguida o sancionada por el mismo hecho, no podía ser aplicado en el presente caso, instruidos los procedimientos e impuestas las sanciones por la Comisión, por una parte, y por las autoridades de un tercer Estado, en concreto los Estados Unidos, por otra, ya que no persiguen los mismos objetivos. Además, si una exigencia de equidad obliga a la Comisión a tener en cuenta, cuando la fijación del importe de una multa, sanciones ya infligidas a la empresa de que se trate por infracciones al Derecho de ententes de un Estado miembro, el Tribunal estima que tal obligación no pesa sobre la Comisión en la hipótesis de que las sanciones ya fijadas emanen de autoridades o tribunales de un tercer Estado (STPI 9 julio 2003, Archer Daniels Midland Company y Archer Daniels Midland Ingredients Ltd/Comisión, T-224/00, apartados 2 a 4, 7, 9, 10 y 85 a 104). 
si es aplicable en las relaciones de la European Competition Network de los Estados miembros: ¿Podría, ad ex., la autoridad de un Estado miembro sancionar una conducta de una empresa que ha sido absuelta por la autoridad de otro Estado comunitario?

61. Hoy en día, no puede haber más que una respuesta: Es poco probable que el principio non bis in idem sea aplicable en la red de autoridades de competencia de los Estados miembros. Hay una buena razón para ello: Dichas autoridades conocen exclusivamente de los efectos en su territorio de los actos colusorios y sus decisiones tienen efecto territorial ${ }^{47}$.

62. Sólo podría plantearse la aplicabilidad de la regla non bis in idem si dichas autoridades también estuvieran facultadas para instruir y sancionar los efectos colusorios de tales actos fuera de sus territorios. Pero - al margen del debate doctrinal - ésta es una cuestión que el Derecho internacional general no prevé sin el consentimiento del Estado miembro afectado y que la UE aún no ha resuelto satisfactoriamente ${ }^{48}$. Sirve, en todo caso, de paliativo el hecho de que, cuando un comportamiento colusorio implica a más Estados miembros, se atribuye su conocimiento a la Comisión ${ }^{49}$.

63. La doctrina italiana, en particular, ha puesto de relieve que:

1. $\left.{ }^{\circ}\right)$ Es incoherente con el espíritu de la reforma acometida por el Reglamento 1/2003 que las decisiones de las autoridades nacionales - a las que se confieren poderes semejantes a los de la Comisión - produzcan efectos únicamente en su territorio nacional.

2. $\left.{ }^{\circ}\right)$ Sería necesario modificar el Reglamento $1 / 2003$ para asegurar el reconocimiento comunitario de las decisiones de cualquier autoridad nacional, las obligaciones de recíproca asistencia y colaboración en el interior de la ECN (no simples facultades) y la supresión de la disparidad de las sanciones que pueden dictar las autoridades de los Estados miembros ${ }^{50}$.

47 En este sentido, Behar-Touchais, M., «Internormativité et droit de la concurrence», Petites affiches, 5 oct. 2004, n. ${ }^{\circ}$ 199, p. 58; SurA, M., «VO Nr. 1/2003», en LangeN/BunTe, Kommentar zum deutschen und europäischen Kartellrecht, 10. ${ }^{\mathrm{a}} \mathrm{ed} .$, vol. 2, München, 2006, pp. 589 y ss., concr. pp. 770-771.

48 En contra, vid. EILMANSBERGER, T., «Ne bis in idem und die Zuständigkeitsverteilung im Netzwerk der Wettbewerbsbehörden», en KöcK, H.F. (Hrsg.), Europarecht im Zeitalter der Globalisierung. Festschrift für Peter Fischer, Wien, 2004, pp. 48-49.

49 Sura, M., «VO Nr. 1/2003», en LANGEN/BunTE, Kommentar zum deutschen und europäischen Kartellrecht, 10. ${ }^{\mathrm{a}}$ ed., vol. 2, München, 2006, pp. 589 y ss., concr. pp. 770-771.

50 Vergnano, E., «Competenze parallele e ne bis in idem: principi concorrenti nella nuova regolamentazione antitrust», Diritto pubblico comparato ed europeo, 2005, III, pp. 14441445. 